\title{
Decompression of lumbar canal stenosis with a bilateral interlaminar versus classic laminectomy technique: a prospective randomized study
}

\author{
Mohamed A. R. Soliman, MD, MSc, and Ahmed Ali, MD, MSc \\ Department of Neurosurgery, Cairo University, Cairo, Egypt
}

\begin{abstract}
OBJECTIVE The aim of this study was to compare the radiological and clinical results of bilateral interlaminar canal decompression and classic laminectomy in lumbar canal stenosis (LCS).

METHODS Two hundred eighteen patients with LCS were randomized to surgical treatment with classic laminectomy (group 1) or bilateral interlaminar canal decompression (group 2). Low-back and leg pain were evaluated according to the visual analog scale (VAS) both preoperatively and postoperatively. Disability was evaluated according to the Oswestry Disability Index (ODI) preoperatively and at 1 month, 1 year, and 3 years postoperatively. Neurogenic claudication was evaluated using the Zurich Claudication Questionnaire (ZCQ) preoperatively and 1 year postoperatively. The two treatment groups were compared in terms of neurogenic claudication, estimated blood loss (EBL), and intra- and postoperative complications.
\end{abstract}

RESULTS Postoperative low-back and leg pain declined as compared to the preoperative pain. Both groups had significant improvement in VAS, ODI, and ZCQ scores, and the improvements in ODI and back pain VAS scores were significantly better in group 2. The average EBL was $140 \mathrm{ml}$ in group 2 compared to $260 \mathrm{ml}$ in group 1. Nine patients in the laminectomy group developed postoperative instability requiring fusion compared to only 4 cases in the interlaminar group $(p=0.15)$. Complications frequency did not show any statistical significance between the two groups.

CONCLUSIONS Bilateral interlaminar decompression is an effective method that provides sufficient canal decompression with decreased instability in cases of LCS and increases patient comfort in the postoperative period.

https://thejns.org/doi/abs/10.3171/2019.2.FOCUS18725

KEYWORDS lumbar canal stenosis; bilateral interlaminar; spinal decompression; minimally invasive surgery

$\mathrm{L}$ UMBAR canal stenosis (LCS) is common in the elderly as a result of hypertrophy of the ligamentum flavum, spine aging, disc degeneration, facet joint growth, and osteophytes constricting the spinal canal and resulting in nerve root compression. ${ }^{3}$ The main symptoms are low-back pain and leg pain and numbness that increase with exertion (neurogenic claudication). ${ }^{31}$ When patients do not respond to conservative treatment, surgery is indicated. ${ }^{2}$ As technology advances, minimally invasive approaches are increasing. One of these minimally invasive methods is bilateral interlaminar canal decompression. ${ }^{40}$ In this study, we compare the radiological and clinical results obtained in classic decompressive laminectomy cases and those achieved in bilateral interlaminar decompression cases.
A classic decompressive laminectomy is the most common surgical approach for LCS decompression. It permits maximal operative decompression of the neural canal and/ or bilateral foramina, but there is damage to the paraspinal muscles, the posterior bone compartment, the supraspinous ligament, the interspinous ligament, and occasionally the capsular facet. ${ }^{2,3,31,40}$

Many techniques have been described for LCS decompression including microhemilaminotomy, interlaminar microdecompression, intersegmental microdecompression, recapturing microlaminoplasty, and segmental microsublaminoplasty. ${ }^{28}$ In particular, unilateral ${ }^{13}$ and bilateral laminotomy have been described for bilateral canal decompression. ${ }^{20,23}$

The microsurgical method is ideal for sufficient bilat-

ABBREVIATIONS EBL = estimated blood loss; LCS = lumbar canal stenosis; ODI = Oswestry Disability Index; VAS = visual analog scale; ZCQ = Zurich Claudication 
eral decompression of the spinal canal or foramen, with minimal paraspinal muscle separation. Thus, it helps to stabilize the spine while the vital bones and soft tissues are secured and at the same time decompressing the spinal canal and/or foramen. ${ }^{13}$

Success rates of the microsurgical methods are as high as $90 \%$; however, studies reporting these rates were without a control group, had few patients with not necessarily the same symptoms, or were retrospective. ${ }^{34}$ Some investigators did not find a significant advantage to the microsurgical methods over the classic laminectomy. ${ }^{27}$ Moreover, in the few qualified studies, investigators reported a higher incidence of preoperative neurological morbidity.

As a result, some authors of a systematic review concluded that laminectomies should be reserved for severe LCS cases. ${ }^{6}$ This study had a sufficiently sized population with comparative data; however, it was not a prospective trial. Our aim in the current prospective study was to compare the clinical outcomes and safety between bilateral interlaminar decompression and classic laminectomy in patients with LCS.

\section{Methods}

Ethics committee approval to perform this study was obtained. Among 597 patients with LCS who were seen in the neurosurgery department throughout a 24-month period, 218 (mean age 53.5 years, range 41-63 years) were unresponsive to conservative measures, fit our study inclusion criteria, and were randomized to treatment with classic laminectomy (109 patients) or bilateral interlaminar canal decompression (109 patients) (Fig. 1). The following inclusion criteria were used: 1) neuroimaging findings of degenerative LCS, 2) symptoms of radiculopathy or neurogenic claudication, 3) absence of other pathology such as instability or disc herniation, 4) no history of lumbar fusion or LCS surgery, and 5) no history of arthritis or heavy smoking (20 cigarettes/day). All patients had undergone a trial of nonsteroidal antiinflammatory drugs and physical therapy for at least 12 weeks without enough improvement.

Spinal instability was defined as $5 \mathrm{~mm}$ or more of translation on sagittal flexion-extension radiographs. ${ }^{8}$

\section{Preoperative Assessment}

On admission, all patients underwent full neurological and clinical assessment, and average pain in the last month prior to admission was self-assessed for the low back and legs according to a 10-point visual analog scale (VAS). ${ }^{29}$ Disability was self-assessed according to the Oswestry Disability Index (ODI) questionnaire, ${ }^{9}$ and neurogenic claudication was assessed using the Zurich Claudication Questionnaire (ZCQ). ${ }^{32}$

Radiological examination involved MRI (Fig. 2) for all patients and postoperative CT scanning (Fig. 3) for confirmation of adequate decompression of the involved segments.

\section{Randomization Plan}

Informed consent was obtained from every patient. A blinded person from the study (resident) gave every pa- tient who met the inclusion criteria a number according to their sequence on admission, which was used for the randomization. The even-number group was operated on via bilateral interlaminar decompression, and the odd-number group was operated on via classic laminectomy.

\section{Operations}

Surgery was performed with the patient under general anesthesia and in the prone position for both procedures and using the operating microscope in the bilateral interlaminar decompression procedure. Undercutting of the facet joints was used in both groups to diminish the facet joint resection. To evaluate the adequacy of decompression, postoperative $\mathrm{CT}$ scans were obtained in all patients.

\section{Classic Laminectomy: Group 1}

The laminae and spinous process of the stenotic segment(s) and the medial end of the facet joint were resected. ${ }^{7}$

\section{Bilateral Interlaminar Canal Decompression: Group 2}

A midline skin incision was sharply made over the intended levels through subcutaneous tissue. The lumbar fascia was then encountered and incised bilaterally. In a subperiosteal fashion, the musculature was elevated off the lamina without disturbing the facet capsule. The microscope was brought into the field, and the remainder of the procedure was done with microscopic visualization. Resection of the lower end of the superior lamina and a small part of the superior end of the inferior lamina was followed by excision of the ligamentum flavum to expose the canal. To expand the lateral recess, resection of the medial end of the facet joint was also done. The spinous process, a considerable percentage of the lamina, and the supra- and interspinous ligaments were conserved. . $^{40,23}$

\section{Assessment of the Surgical Procedure}

Intraoperative factors such as duration of the technique, estimated blood loss (EBL), and other intraoperative issues were noted. Perioperative morbidity included the occurrence of nerve injury and any reoperations in the 3 years since surgery.

\section{Outcome Evaluation}

For the proper assessment of pain in the back and legs, VAS scores were recorded at follow-ups 1 month, 1 year, and 3 years after surgery. The ODI scores were recorded at 1 month, 1 year, and 3 years after surgery, and neurogenic claudication (ZCQ) scores were recorded at 1 year. The results were evaluated by a statistician. MRI and flexion-extension radiography were performed in patients showing recurrent symptoms or substantial residual stenosis. In cases of residual or adjacent-level stenosis and instability, surgical intervention occurred and was documented.

\section{Statistical Analysis}

The unpaired Student t-test, Fisher exact test, and chisquare test were used as appropriate to analyze differences 


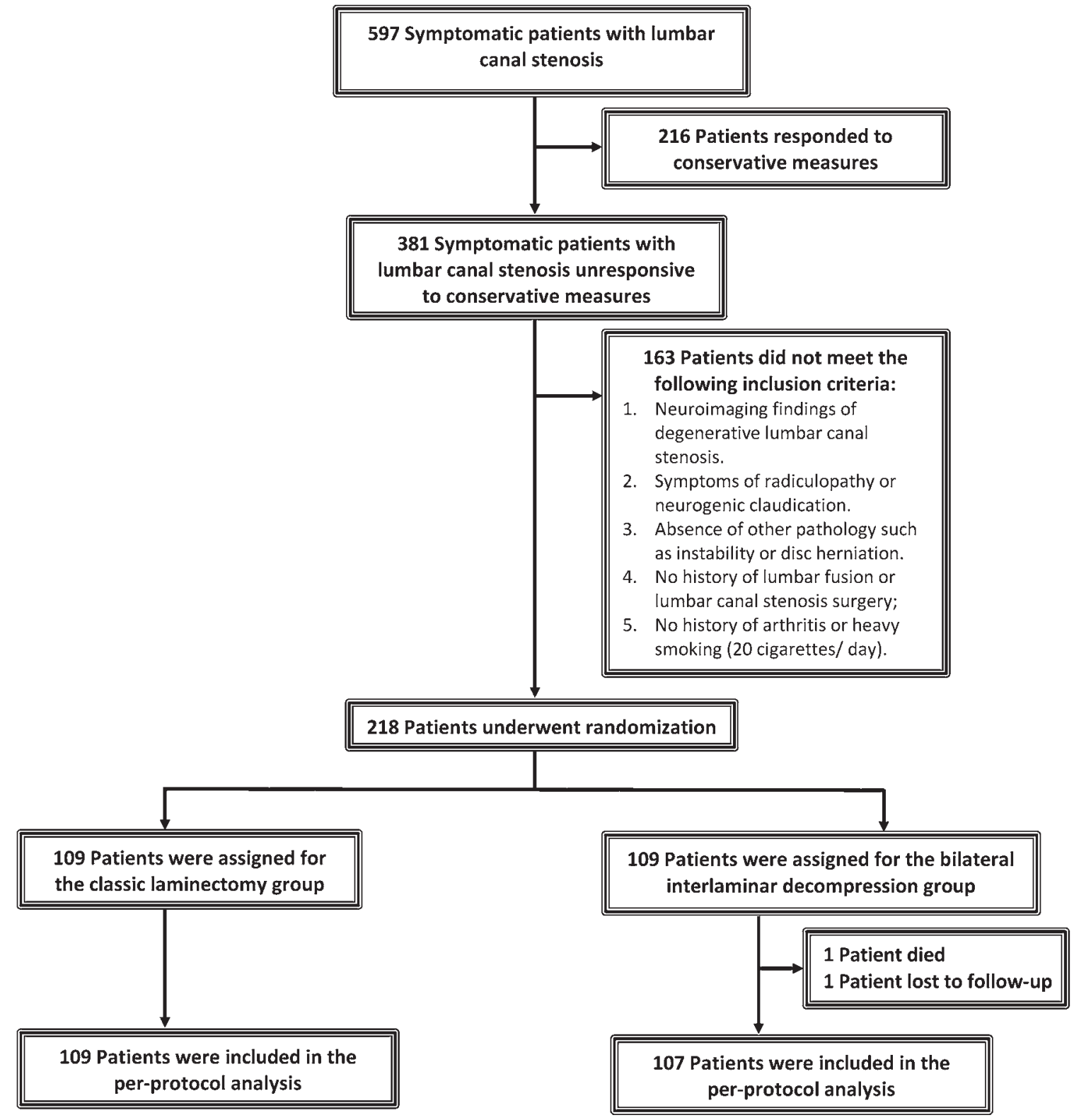

FIG. 1. Flow process: enrollment, randomization, treatment, and 3-year follow-up.

in the preoperative demographic characteristics (age, sex, weight, and spinal levels involved), clinical presentations (preoperative ODI, ZCQ, and VAS scores), and clinical outcomes (postoperative complications and ODI, ZCQ, and VAS scores) between the two groups. The paired Student t-test was used to analyze variations in each group over a period of time. Statistical significance was established at $\mathrm{p}<0.05$.

\section{Results}

There were no significant preoperative dissimilarities between the two groups of patients (Table 1). Preoperative low-back and leg pain scores (VAS) were recorded (Table 2); there were no significant variances in the preoperative pain features between the groups. The mean preoperative neurogenic claudication duration was 26.4 months.

\section{Pain Assessment}

Surgical canal decompression led to a marked decrease in total pain compared to the preoperative pain in both groups ( $<$ 0.001). Preoperative average back pain scores on the VAS were $6.82 \pm 1.18$ in group 1 and $6.56 \pm 1.08$ in group 2, and preoperative average leg pain scores were $8.06 \pm 0.94$ and $7.91 \pm 0.94$, respectively (Table 2 and Fig. 4A). These preoperative scores were not significantly different between the groups. The remaining overall average back pain scores on the VAS were $5.85 \pm 1.37,5.35 \pm 0.99$, and $3.08 \pm 1.02$ in group 1 at 1 month, 1 year, and 3 years, 


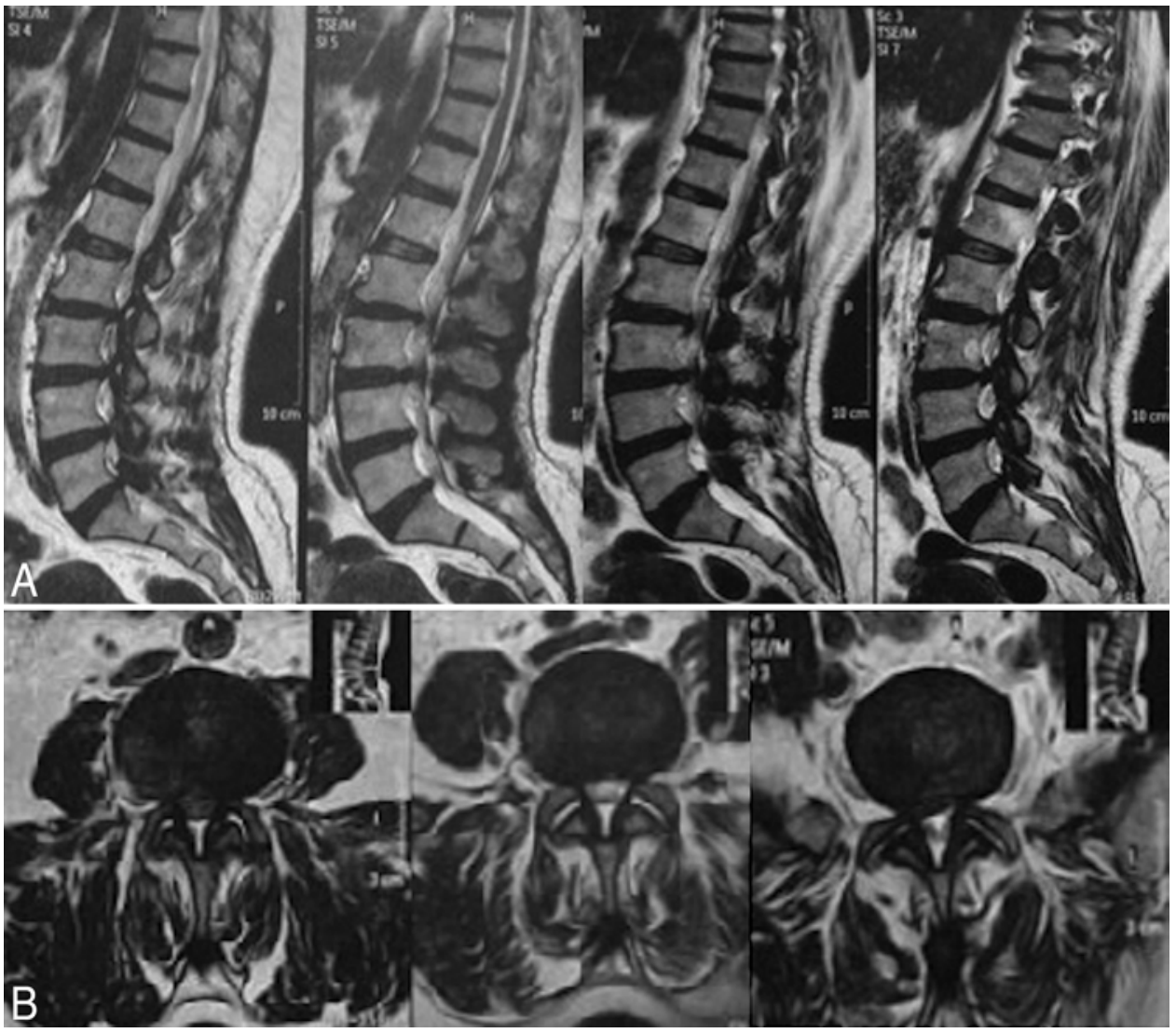

FIG. 2. Preoperative MRI of the lumbar spine: sagittal $(\mathbf{A})$ and axial $(\mathbf{B})$ views.

respectively, compared with $3.02 \pm 1.12,1.92 \pm 0.85$, and $1.37 \pm 0.6$, respectively, in group 2 . With regard to back pain, compared to the preoperative pain, both groups had significant improvement on the VAS $(\mathrm{p}<0.001)$, and the improvements were significantly better in group $2(\mathrm{p}<$ 0.001 ), which may have been attributable to less muscle dissection and less bony removal. The remaining overall average leg pain scores on the VAS were $2.35 \pm 1.01,1.39$ \pm 0.82 , and $1.08 \pm 0.31$ in group 1 at 1 month, 1 year, and 3 years, respectively, compared with $2.3 \pm 0.95,1.37 \pm 0.54$, and $1.17 \pm 0.38$, respectively, in group $2(\mathrm{p}>0.05)$. With regard to the leg pain, compared to the preoperative pain, both groups had significant improvement on the VAS ( $p<$ $0.001)$, and there was no significant difference between the two groups ( $p>0.05$; Fig. 4B).

\section{Disability Assessment}

There was a marked decrease in total disability after surgical canal decompression in both groups, as compared to the preoperative disability $(\mathrm{p}<0.001)$. The preoperative average disability scores on the ODI were $33.77 \pm 5.65$ in group 1 and $32.22 \pm 5.37$ in group 2 . The remaining overall average disability scores on the ODI were $16.6 \pm$ $7.03,14.73 \pm 6.36$, and $14.06 \pm 6.27$ in group 1 at 1 month, 1 year, and 3 years, respectively, compared with $13.62 \pm$ $5.75,11.63 \pm 4.82$, and $10.98 \pm 5.17$, respectively, in group 2 . There was no significant difference in preoperative dis- ability between the groups (Table 2). Improvements on the ODI were significantly better in group $2(\mathrm{p}<0.001)$.

\section{Neurogenic Claudication}

Neurogenic claudication, which is the most common symptom of LCS, improved after surgery in both groups according to the ZCQ $(\mathrm{p}<0.001)$. Preoperative mean symptom severity and physical function on the ZCQ were not significantly different between the groups (Table 2). Symptom severity and physical function scores improved at the 1-year postoperative visit in both groups. The mean patient satisfaction scores according to the ZCQ were 2.25 \pm 0.69 in group 1 and $2.1 \pm 0.7$ in group $2(p=0.11)$. There was no significant difference between the groups except in postoperative symptom severity, which was higher in group 1 ( $\mathrm{p}<0.001)$ mainly due to high scores in the back pain questions.

\section{Levels Involved}

We detected multisegmental stenosis in the majority of patients, with an overall mandatory decompression of 414 levels (Table 1). The L3-4 and the L4-5 levels were most commonly involved (96 [23\%] and 95 [23\%] of cases, respectively). The maximum number of levels decompressed was four in each group. The mean number of levels decompressed was $1.92 \pm 0.58$ in group 1 and 1.88 \pm 0.59 in group 2 . 


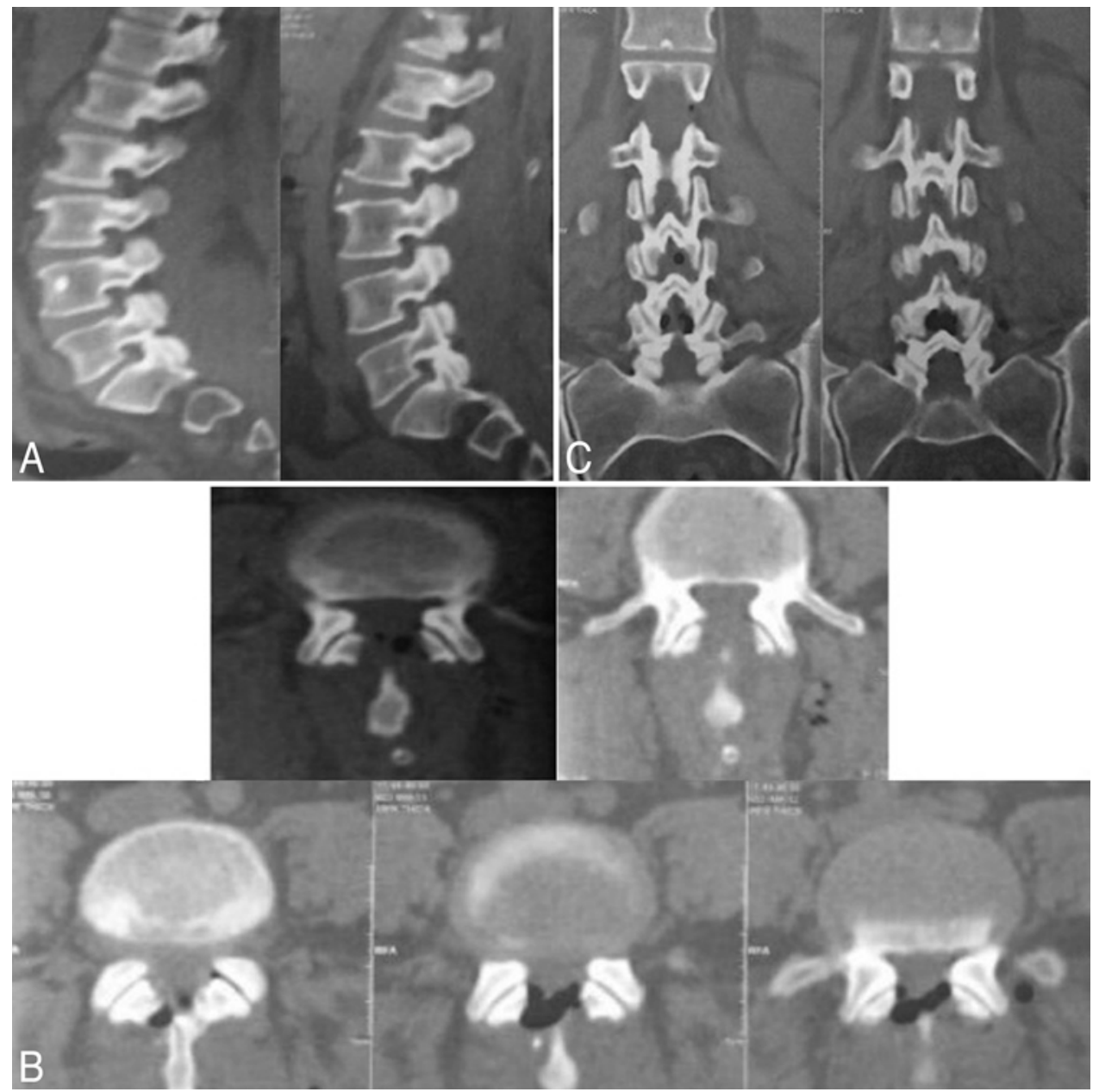

FIG. 3. Postoperative CT of the lumbar spine: sagittal (A), axial (B), and coronal (C) views.

\section{Intraoperative Parameters}

The planned technique was followed in all patients, and lumbar canal decompression was sufficiently attained in all surgical cases. The operation's mean time per level was significantly longer for group 2 (112 vs 64 minutes in group 1, p < 0.001; Fig. 4C). The mean EBL was lower in patients in group 2 (140 vs $260 \mathrm{ml} /$ level in group 1; Fig. 4D). No patient in group 2 required a blood transfusion, whereas 1 patient in group 1 required a blood transfusion because of intraoperative blood loss.

\section{Intraoperative Complications}

Unintended durotomy occurred in 9 cases in group 1 and 4 cases in group 2 ( $\mathrm{p}=0.15$; Table 3 and Fig. 4E). Dural tears were associated with an increased duration of surgery. The tears were managed by direct stitching, and no subsequent postoperative CSF fistula was detected. Seven cases in group 2 had an epidural hematoma needing reoperation ( $p=0.007)$, which was recognized on MRI. Three cases in group 1 and 1 case in group 2 had a postoperative radicular deficit $(\mathrm{p}=0.31)$.

Four wound infections were noted in group 1 (3 deep and 1 superficial) and 11 cases in group 2 (all superficial; $p$ $=0.06$; Fig. 4F). We did not have any perioperative deaths.

\section{Follow-Up}

Follow-ups were conducted 1 month, 1 year, and 3 years after the operation. In that period, 1 patient died of unrelated reasons 26 months after surgery and 1 patient was lost to follow-up within 3 years after surgery (both were in group 2); therefore, 216 patients were followed up for 3 years.

\section{Necessary Reoperations}

All the patients had adequate canal decompression, which was seen on the postoperative CT scan and was reported by the radiologist. Reoperation was required for recurrent or residual LCS in the same segment within 3 years in 1 patient in group 1 and 2 cases in group 2. Postoperative instability necessitated fusion surgery in 9 patients in group 1 and 4 patients in group 2. Overall, the reoperation rate between the groups was nearly the same $(\mathrm{p}=0.15$; Fig. $4 \mathrm{G})$. 
TABLE 1. Demographic and clinical characteristics of patient groups

\begin{tabular}{lccc}
\hline \multicolumn{1}{c}{ Variable } & $\begin{array}{c}\text { Group 1 } \\
\text { (classic } \\
\text { laminectomy) }\end{array}$ & $\begin{array}{c}\text { Group 2 } \\
\text { (bilat interlaminar } \\
\text { decompression) }\end{array}$ & $\begin{array}{c}\mathrm{p} \\
\text { Value }\end{array}$ \\
\hline No. & 109 & 107 & \\
\hline Age in yrs & $52.88 \pm 4.19$ & $54.21 \pm 4.54$ & 0.0256 \\
\hline Males & $55 \%$ & $52.3 \%$ & 0.68 \\
\hline Weight in kg & $89.75 \pm 7.4$ & $88.65 \pm 6.9$ & 0.26 \\
\hline $\begin{array}{l}\text { No. of levels decom- } \\
\text { pressed }\end{array}$ & 209 & 205 & 0.49 \\
\hline $\begin{array}{l}\text { Mean no. of levels } \\
\text { decompressed }\end{array}$ & $1.92 \pm 0.58$ & $1.88 \pm 0.59$ & \\
\hline $\begin{array}{l}\text { Mean EBL/level in ml } \\
\text { Mean surgical time/ } \\
\text { level in mins }\end{array}$ & $260 \pm 75$ & $140 \pm 44$ & $<0.001$ \\
\hline
\end{tabular}

\section{Discussion}

Following our experience and with the aid of previous studies that have reported on the effectiveness of bilateral interlaminar decompression, we report the results of the first randomized prospective study comparing bilateral

TABLE 2. Clinical outcomes: VAS, ODI, and ZCQ scores

\begin{tabular}{|c|c|c|c|}
\hline Scale & Group 1 & Group 2 & $\mathrm{p}$ Value \\
\hline \multicolumn{4}{|l|}{ VAS low back } \\
\hline Preop & $6.82 \pm 1.18$ & $6.56 \pm 1.08$ & 0.091 \\
\hline \multicolumn{4}{|l|}{ Postop } \\
\hline $1 \mathrm{mo}$ & $5.85 \pm 1.37$ & $3.02 \pm 1.12$ & $<0.001$ \\
\hline $1 \mathrm{yr}$ & $5.35 \pm 0.99$ & $1.92 \pm 0.85$ & $<0.001$ \\
\hline 3 yrs & $3.08 \pm 1.02$ & $1.37 \pm 0.6$ & $<0.001$ \\
\hline \multicolumn{4}{|l|}{ VAS leg } \\
\hline Preop & $8.06 \pm 0.94$ & $7.91 \pm 0.94$ & 0.24 \\
\hline \multicolumn{4}{|l|}{ Postop } \\
\hline $1 \mathrm{mo}$ & $2.35 \pm 1.01$ & $2.3 \pm 0.95$ & 0.71 \\
\hline $1 \mathrm{yr}$ & $1.39 \pm 0.82$ & $1.37 \pm 0.54$ & 0.83 \\
\hline 3 yrs & $1.08 \pm 0.31$ & $1.17 \pm 0.38$ & 0.057 \\
\hline \multicolumn{4}{|l|}{ ODI } \\
\hline Preop & $33.77 \pm 5.65$ & $32.22 \pm 5.37$ & 0.0391 \\
\hline \multicolumn{4}{|l|}{ Postop } \\
\hline $1 \mathrm{mo}$ & $16.6 \pm 7.03$ & $13.62 \pm 5.75$ & $<0.001$ \\
\hline $1 \mathrm{yr}$ & $14.73 \pm 6.36$ & $11.63 \pm 4.82$ & $<0.001$ \\
\hline 3 yrs & $14.06 \pm 6.27$ & $10.98 \pm 5.17$ & $<0.001$ \\
\hline \multicolumn{4}{|l|}{ ZCQ } \\
\hline \multicolumn{4}{|l|}{ Preop } \\
\hline Symptom severity & $3.5 \pm 0.63$ & $3.38 \pm 0.66$ & 0.17 \\
\hline Physical function & $2.66 \pm 0.7$ & $2.61 \pm 0.62$ & 0.58 \\
\hline \multicolumn{4}{|l|}{ Postop (1 yr) } \\
\hline Symptom severity & $2.85 \pm 0.8$ & $2.05 \pm 0.66$ & $<0.001$ \\
\hline Physical function & $1.74 \pm 0.7$ & $1.7 \pm 0.71$ & 0.68 \\
\hline Patient satisfaction & $2.25 \pm 0.69$ & $2.1 \pm 0.7$ & 0.11 \\
\hline
\end{tabular}

TABLE 3. Perioperative complications

\begin{tabular}{llcl}
\hline \multicolumn{1}{c}{ Complication } & Group 1 & Group 2 & p Value \\
\hline Dural tear & $9(8.3 \%)$ & $4(3.7 \%)$ & 0.15 \\
\hline Epidural hematoma & $0(0 \%)$ & $7(6.5 \%)$ & 0.007 \\
\hline Radicular deficit & $3(2.8 \%)$ & $1(0.9 \%)$ & 0.31 \\
\hline Wound infection & $4(3.7 \%)$ & $11(10.3 \%)$ & 0.06 \\
\hline
\end{tabular}

interlaminar decompression with laminectomy in 218 patients with LCS.

\section{Demographics}

Degenerative LCS is seen more often in people ages 60 and above. ${ }^{14}$ The most common surgery for LCS is laminectomy and bilateral partial facetectomy. While this approach is satisfactory in alleviating the symptoms of neurogenic claudication, the risk of new-onset spondylolisthesis is reported to be as high as $31 \% .^{10}$ Progression of spondylolisthesis is evident on radiography if resection of greater than $50 \%$ of the facet joint was done at any level. ${ }^{1}$

\section{Surgical Approach}

The benefit of classic laminectomy is the adequate working space that it offers through the removal of the posterior elements, including the spinous process, interspinous ligament, and supraspinous ligament, which enables good visibility. A disadvantage of the classic laminectomy includes resection of the osteoligamentous complex, which may cause trunk extensor weakness and secondary spinal instability. The classic laminectomy has a success rate of only $64 \%$, significant intraoperative bleeding, and perioperative complications such as incisional pain after surgery, longer recovery time, disturbance of the normal anatomy, and perhaps failed back syndrome. ${ }^{38}$

The benefit of minimally invasive methods is the possible preservation of the osteoligamentous complex; however, these methods still involve disturbance of the paraspinal musculature and the risk of neural injury especially in patients with tight LCS. 17,33,38 The advantage of bilateral canal decompression over classic laminectomy is preservation of the posterior ligamentous complex, which stabilizes lumbar motion and acts as a tension band. The disadvantage of bilateral canal decompression is the smaller operational space encountered and the possible prolongation of operative time because of technical difficulty. In addition, if unintended durotomy occurs, a complete laminectomy may be obligatory to adequately visualize and repair the dural defect. ${ }^{34}$ In 1993 Postacchini et al. recommended bilateral laminotomy as acceptable for mild to moderate stenosis, whereas laminectomy was favored for severe stenosis or spondylolisthesis. ${ }^{27}$ These authors maintained that bilateral laminotomy must not be routinely done with severe stenosis. The clinical decision is affected by the severity of stenosis,${ }^{35}$ medical comorbidity,${ }^{18}$ the liquid inside the facets, ${ }^{1}$ facet tropism, ${ }^{21}$ and segmental mobility before surgery. ${ }^{24}$

More modified techniques have been planned by numerous authors, especially unilateral and bilateral laminotomy for bilateral canal decompression, with reported 

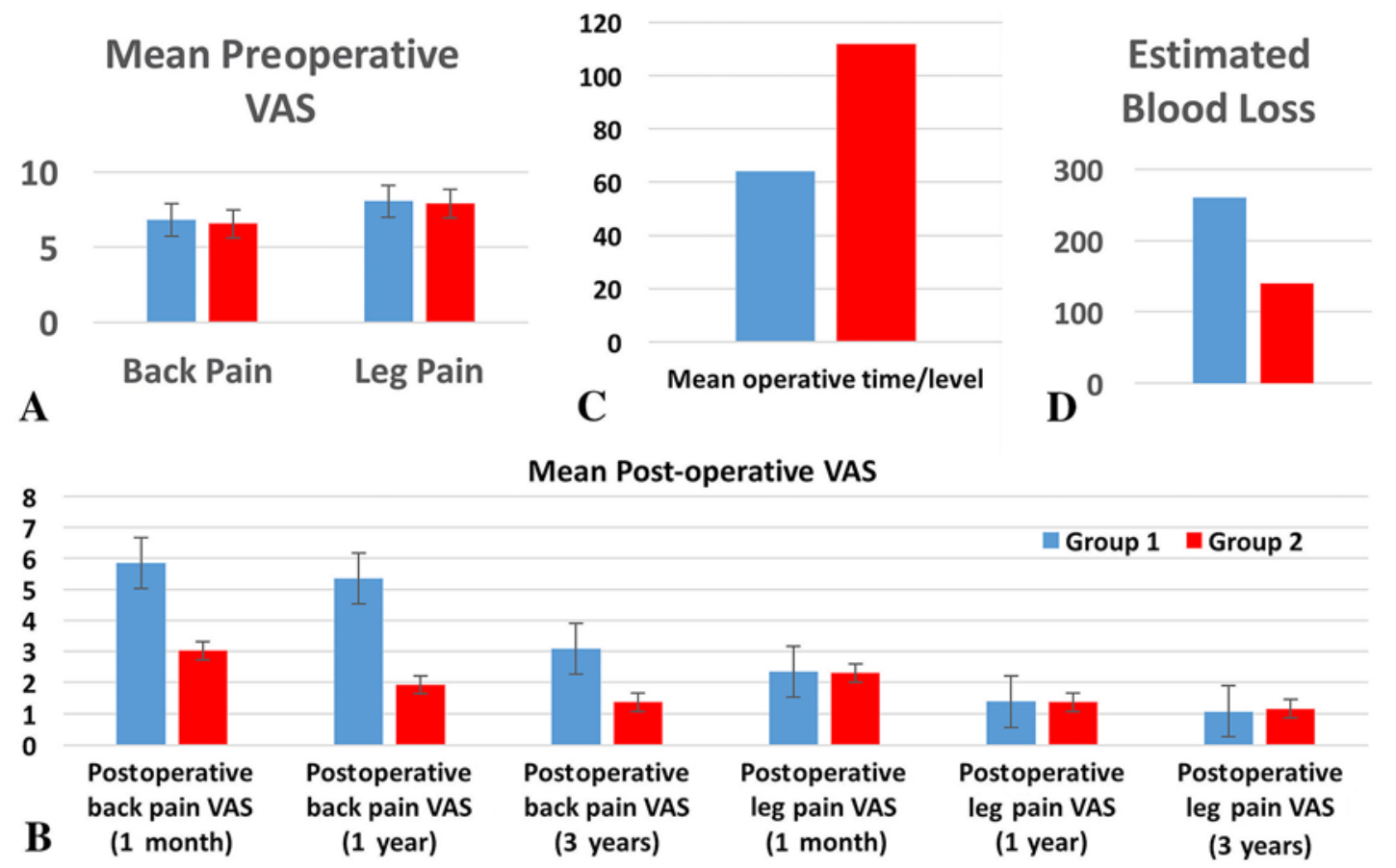

Mean Post-operative VAS
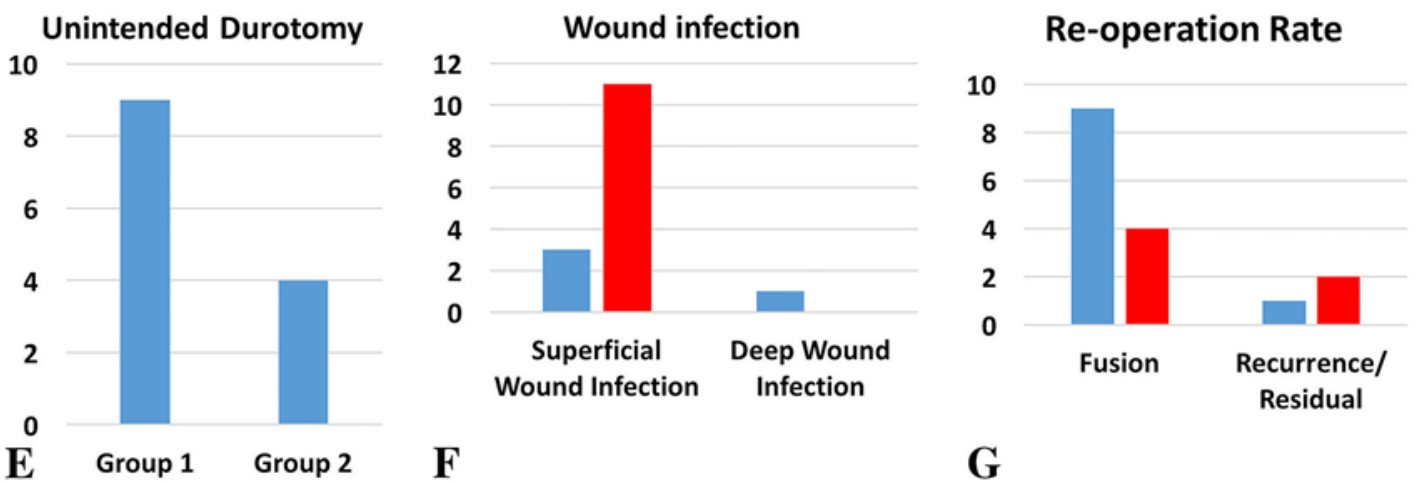

FIG. 4. Bar graphs depicting mean preoperative back and leg pain scores (VAS, A); mean postoperative back and leg pain scores (VAS) at 1 month, 1 year, and 3 years after surgery (B); mean operative time (C); mean EBL (measured in ml; D); number of unintended durotomies $(\mathbf{E})$; number of superficial and deep wound infections $(\mathbf{F})$; and number of patients needing reoperation $(\mathbf{G})$.

success rates of $60 \%-80 \%$. The advantage of unilateral and bilateral laminotomy over classic laminectomy is reduced pain postoperatively, improved health-related quality of life, and no need for fusion surgery later on. ${ }^{25,33,39}$ The interlaminar decompression has the benefit of conserving the inferior levels of the paraspinal muscle from atrophy due to the reduction of muscle injury. ${ }^{15}$

\section{Clinical Outcome}

Thomé et al. reported a randomized study of 120 patients who underwent LCS decompression. ${ }^{33}$ The patients were randomized to three treatment groups: unilateral laminotomy, bilateral laminotomy, and laminectomy. The bilateral laminotomy group had the lowest total complication rate. Ninety-four percent of patients had at least 12 months of follow-up. Residual pain was lowest in the bilateral laminotomy group (VAS score $2.3 \pm 2.4$ and $4 \pm 1$ in laminectomy group, $\mathrm{p}=0.05$; and $3.6 \pm 2.7$ in unilateral laminotomy group, $\mathrm{p}<0.05)$. In most of the cases, bilateral laminotomy produced major advantages, and it proved to be a possible treatment substitute in cases of LCS.

In reviewing the literature on the bilateral interlaminar canal decompression technique, ${ }^{22}$ we found clinical case series showing good results in $91 \%$ of cases in 1 year; $82 \%,{ }^{23} 87 \%,{ }^{12} 78 \%,{ }^{41}$ and $68 \%{ }^{5}$ of cases in 2 years; $85 \%$ of cases in 3 years; and $74 \%{ }^{5}$ of cases in 6 years. Moreover, in a 54-patient prospective outcome study, Kleeman et al. showed patient satisfaction at $100 \%$ and good outcomes at $88 \%$ after 4 years without any deterioration. ${ }^{20}$

In our randomized study, the outcomes confirm that bilateral interlaminar decompression is superior to laminectomy in terms of less postoperative back pain. Fusion was indicated less often in group 2 patients. Long-term analysis of the follow-up data showed that bilateral interlaminar decompression is more beneficial for LCS patients and may reduce the need for further fusion surgery, but 
there was no statistically significant difference in the reoperation rate between the groups $(\mathrm{p}=0.3)$.

Comparative preoperative and postoperative imaging showed adequate decompression in both groups. A comparison of both decompression on imaging and postoperative leg pain (VAS) indicated no significant differences between the groups, which reveals that bilateral canal decompression is sufficient. Furthermore, postoperative low-back pain was statistically worse in the laminectomy group $(\mathrm{p}<0.001)$.

\section{Intraoperative Parameters}

Although bilateral canal decompression's longer operative time seems to be a disadvantage compared to the classic laminectomy, it is believed that the operative time will decline for the bilateral decompression group as the surgeon learning curve improves, as in our study. To avoid complications during surgery, surgeons use fine Kerrison rongeurs instead of a high-speed drill, the latter contributing to a longer operative time. Prolonged surgery time has always been associated with bilateral interlaminar canal decompression ${ }^{27}$ compared to the classic laminectomy. ${ }^{39}$ In our study, the mean operative time was 64 minutes/ level for group 1 compared to 112 minutes/level for group 2 . The longer time was attributed to a lack of experience with the bilateral interlaminar canal decompression approach, which decreased in the cases performed later in our series because of the learning curve. Only 6 surgeons with 4-9 years of neurosurgical experience were involved in these operations. Khoo and Fessler described a surgical time of 109 minutes/level for microendoscopic unilateral laminectomy and 88 minutes/level for classic laminectomy. ${ }^{19}$ Other studies have described less surgical time per level for classic laminectomies. ${ }^{11}$ Although the unfavorable blood loss that necessitates transfusion is infrequent in all lumbar canal decompression procedures, EBL was less in the bilateral interlaminar group..$^{19,26}$

\section{Perioperative Complications}

A spine surgeon's main concern is to decompress the LCS in a minimally invasive manner; however, there has been an increased rate of neural injury. ${ }^{6}, 27$ Verbiest reported that there was increased radicular deficit postoperatively in $5 \%$ of laminectomy patients. ${ }^{36}$ Postacchini et al. reported an increase in radiculopathy postoperatively in $3(11.5 \%)$ of 26 bilateral interlaminar canal decompression patients compared with 1 (3.1\%) of 32 classic laminectomy patients $;{ }^{27}$ however, other studies have reported that radicular deficit occurs in only $1 \%$ of cases when using the bilateral interlaminar canal decompression approach. ${ }^{5}$ Referring to our data, there was no definite injury to the nerve root. Intraoperative compression and/or manipulation of the nerve roots, however, may be the cause of the radicular deficit. We had 3 patients in the classic laminectomy group who had a radicular deficit compared to only 1 patient in the bilateral interlaminar canal decompression group $(p=0.31)$.

In general, incidental durotomy rates for bilateral interlaminar decompression range from $2 \%$ to $6 \%, 20,34,42$ while classic laminectomy may cause dural tears in $5 \%-15 \%$ of cases. ${ }^{30,37}$ In our series, 9 incidental durotomies occurred in group 1 and 4 in group 2, all of which were primarily repaired. When the rates of durotomies were compared, the difference was not statistically significant $(\mathrm{p}=0.15)$.

All spinal surgery cases have a $2 \%$ risk of wound infection, ${ }^{16,30}$ but this complication was more frequent in our study (3.7\% in group 1, three deep and one superficial; and $10 \%$ in group 2, all superficial).

The occurrence of postoperative epidural hematoma ranges from $1 \%$ to $3 \% .^{30,42}$ The incidence of postoperative hematoma after bilateral interlaminar decompression in our study was $6.4 \%$, and there were no cases in the classic laminectomy group.

According to our results, we recommend bilateral interlaminar decompression as a good treatment option for patients with LCS, regardless of the severity of illness or patient age.

\section{Study Limitations}

Among the limitations of this study is the lack of computerized randomization of the patients; however, it was solved by the randomization of patients by a blinded study person. Also, we compared only the classic laminectomy and the bilateral interlaminar canal decompression; bilateral canal decompression through a unilateral approach was not included in this study.

\section{Conclusions}

Bilateral interlaminar decompression permits safe and acceptable spinal canal decompression in patients with LCS. The procedure was associated with increased postoperative comfort and sufficient canal decompression with minimal effect to stability during a long follow-up period of 3 years. Surgeon experience with this approach will help to reduce operation time and complications.

\section{Acknowledgments}

We acknowledge Drs. Ahmed A. Marei and Ahmed Hussein for their help in this study.

\section{References}

1. Abumi K, Panjabi MM, Kramer KM, Duranceau J, Oxland T, Crisco JJ: Biomechanical evaluation of lumbar spinal stability after graded facetectomies. Spine (Phila Pa 1976) 15:1142-1147, 1990

2. Amundsen T, Weber H, Lilleås F, Nordal HJ, Abdelnoor M, Magnaes B: Lumbar spinal stenosis. Clinical and radiologic features. Spine (Phila Pa 1976) 20:1178-1186, 1995

3. Arbit E, Pannullo S: Lumbar stenosis: a clinical review. Clin Orthop Relat Res (384):137-143, 2001

4. Aryanpur J, Ducker T: Multilevel lumbar laminotomies: an alternative to laminectomy in the treatment of lumbar stenosis. Neurosurgery 26:429-433, 1990

5. Askar Z, Wardlaw D, Choudhary S, Rege A: A ligamentum flavum-preserving approach to the lumbar spinal canal. Spine (Phila Pa 1976) 28:E385-E390, 2003

6. Benz RJ, Garfin SR: Current techniques of decompression of the lumbar spine. Clin Orthop Relat Res (384):75-81, 2001

7. Detwiler PW, Spetzler CB, Taylor SB, Crawford NR, Porter RW, Sonntag VK: Biomechanical comparison of facet-sparing laminectomy and Christmas tree laminectomy. J Neurosurg 99 (2 Suppl):214-220, 2003

8. Epstein NE: Decompression in the surgical management of degenerative spondylolisthesis: advantages of a conservative approach in 290 patients. J Spinal Disord 11:116-123, 1998 
9. Fairbank JC, Pynsent PB: The Oswestry Disability Index Spine (Phila Pa 1976) 25:2940-2952, 2000

10. Fox MW, Onofrio BM, Onofrio BM, Hanssen AD: Clinical outcomes and radiological instability following decompressive lumbar laminectomy for degenerative spinal stenosis: a comparison of patients undergoing concomitant arthrodesis versus decompression alone. J Neurosurg 85:793-802, 1996

11. Fredman B, Arinzon Z, Zohar E, Shabat S, Jedeikin R, Fidelman ZG, et al: Observations on the safety and efficacy of surgical decompression for lumbar spinal stenosis in geriatric patients. Eur Spine J 11:571-574, 2002

12. Grob D, Humke T, Dvorak J: Degenerative lumbar spinal stenosis. Decompression with and without arthrodesis. J Bone Joint Surg Am 77:1036-1041, 1995

13. Guiot BH, Khoo LT, Fessler RG: A minimally invasive technique for decompression of the lumbar spine. Spine (Phila Pa 1976) 27:432-438, 2002

14. Haba K, Ikeda M, Soma M, Yamashima T: Bilateral decompression of multilevel lumbar spinal stenosis through a unilateral approach. J Clin Neurosci 12:169-171, 2005

15. Henky J, Yasuda M, Arifin MZ, Takayasu M, Faried A: Trumpet laminectomy microdecompression for lumbal canal stenosis. Asian Spine J 8:667-674, 2014

16. Iguchi T, Kurihara A, Nakayama J, Sato K, Kurosaka M, Yamasaki K: Minimum 10-year outcome of decompressive laminectomy for degenerative lumbar spinal stenosis. Spine (Phila Pa 1976) 25:1754-1759, 2000

17. Jayarao M, Chin LS: Results after lumbar decompression with and without discectomy: comparison of the transspinous and conventional approaches. Neurosurgery 66 (3 Suppl Operative): $152-160,2010$

18. Johnsson KE, Redlund-Johnell I, Udén A, Willner S: Preoperative and postoperative instability in lumbar spinal stenosis. Spine (Phila Pa 1976) 14:591-593, 1989

19. Khoo LT, Fessler RG: Microendoscopic decompressive laminotomy for the treatment of lumbar stenosis. Neurosurgery 51 (5 Suppl):S146-S154, 2002

20. Kleeman TJ, Hiscoe AC, Berg EE: Patient outcomes after minimally destabilizing lumbar stenosis decompression: the "Port-Hole" technique. Spine (Phila Pa 1976) 25:865-870, 2000

21. Lee CK: Lumbar spinal instability (olisthesis) after extensive posterior spinal decompression. Spine (Phila Pa 1976) 8:429-433, 1983

22. Lin PM: Internal decompression for multiple levels of lumbar spinal stenosis: a technical note. Neurosurgery 11:546-549, 1982

23. Nakai O, Ookawa A, Yamaura I: Long-term roentgenographic and functional changes in patients who were treated with wide fenestration for central lumbar stenosis. J Bone Joint Surg Am 73:1184-1191, 1991

24. Natelson SE: The injudicious laminectomy. Spine (Phila Pa 1976) 11:966-969, 1986

25. Oertel MF, Ryang YM, Korinth MC, Gilsbach JM, Rohde $\mathrm{V}$ : Long-term results of microsurgical treatment of lumbar spinal stenosis by unilateral laminotomy for bilateral decompression. Neurosurgery 59:1264-1270, 2006

26. Palmer S, Turner R, Palmer R: Bilateral decompression of lumbar spinal stenosis involving a unilateral approach with microscope and tubular retractor system. J Neurosurg 97 (2 Suppl):213-217, 2002

27. Postacchini F, Cinotti G, Perugia D, Gumina S: The surgical treatment of central lumbar stenosis. Multiple laminotomy compared with total laminectomy. J Bone Joint Surg Br 75:386-392, 1993

28. Sanderson PL, Getty CJ: Long-term results of partial undercutting facetectomy for lumbar lateral recess stenosis. Spine (Phila Pa 1976) 21:1352-1356, 1996

29. Scott J, Huskisson EC: Graphic representation of pain. Pain 2:175-184, 1976
30. Silvers HR, Lewis PJ, Asch HL: Decompressive lumbar laminectomy for spinal stenosis. J Neurosurg 78:695-701, 1993

31. Sirvanci M, Bhatia M, Ganiyusufoglu KA, Duran C, Tezer M, Ozturk C, et al: Degenerative lumbar spinal stenosis: correlation with Oswestry Disability Index and MR imaging. Eur Spine J 17:679-685, 2008

32. Stucki G, Daltroy L, Liang MH, Lipson SJ, Fossel AH, Katz $\mathrm{JN}$ : Measurement properties of a self-administered outcome measure in lumbar spinal stenosis. Spine (Phila Pa 1976) 21:796-803, 1996

33. Thomé C, Zevgaridis D, Leheta O, Bäzner H, Pöckler-Schöniger $\mathrm{C}$, Wöhrle J, et al: Outcome after less-invasive decompression of lumbar spinal stenosis: a randomized comparison of unilateral laminotomy, bilateral laminotomy, and laminectomy. J Neurosurg Spine 3:129-141, 2005

34. Tsai RY, Yang RS, Bray RS Jr: Microscopic laminotomies for degenerative lumbar spinal stenosis. J Spinal Disord 11:389-394, 1998

35. Verbiest H: A radicular syndrome from developmental narrowing of the lumbar vertebral canal. J Bone Joint Surg Br 36-B:230-237, 1954

36. Verbiest H: Results of surgical treatment of idiopathic developmental stenosis of the lumbar vertebral canal. A review of twenty-seven years' experience. J Bone Joint Surg Br 59:181-188, 1977

37. Wang JC, Bohlman HH, Riew KD: Dural tears secondary to operations on the lumbar spine. Management and results after a two-year-minimum follow-up of eighty-eight patients. J Bone Joint Surg Am 80:1728-1732, 1998

38. Watanabe K, Matsumoto M, Ikegami T, Nishiwaki Y, Tsuji T, Ishii K, et al: Reduced postoperative wound pain after lumbar spinous process-splitting laminectomy for lumbar canal stenosis: a randomized controlled study. J Neurosurg Spine 14:51-58, 2011

39. Weiner BK, Walker M, Brower RS, McCulloch JA: Microdecompression for lumbar spinal canal stenosis. Spine (Phila Pa 1976) 24:2268-2272, 1999

40. Yang B, Chen R, Xie P, Liu B, Dong J, Rong L: [Microendoscopic decompression via unilateral approach for lumbar spinal stenosis.] Zhongguo Xiu Fu Chong Jian Wai Ke Za Zhi 25:1158-1163, 2011 (Chinese)

41. Yone K, Sakou T: Usefulness of Posner's definition of spinal instability for selection of surgical treatment for lumbar spinal stenosis. J Spinal Disord 12:40-44, 1999

42. Young S, Veerapen R, O'Laoire SA: Relief of lumbar canal stenosis using multilevel subarticular fenestrations as an alternative to wide laminectomy: preliminary report. Neurosurgery 23:628-633, 1988

\section{Disclosures}

The authors report no conflict of interest concerning the materials or methods used in this study or the findings specified in this paper.

\section{Author Contributions}

Conception and design: both authors. Acquisition of data: both authors. Analysis and interpretation of data: both authors. Drafting the article: both authors. Critically revising the article: both authors. Reviewed submitted version of manuscript: both authors Approved the final version of the manuscript on behalf of both authors: Soliman. Statistical analysis: Soliman. Administrative/ technical/material support: Ali. Study supervision: Ali.

\section{Correspondence}

Mohamed A. R. Soliman: Cairo University, Cairo, Egypt. moh.ar.sol@kasralainy.edu.eg. 